\title{
Effect of Equal Channel Angular Pressing on the Surface Roughness of Solid State Recycled Aluminum Alloy 6061 Chips
}

\author{
Adel Taha Abbas, ${ }^{1}$ Mohamed Adel Taha, ${ }^{2}$ Adham Ezzat Ragab, ${ }^{3}$ \\ Ehab Adel El-Danaf, ${ }^{1}$ and Mohamed Ibrahim Abd El Aal ${ }^{2}$ \\ ${ }^{1}$ Department of Mechanical Engineering, College of Engineering, King Saud University, Riyadh, Saudi Arabia \\ ${ }^{2}$ Department of Mechanical Design and Production, College of Engineering, Zagazig University, Sharkia, Egypt \\ ${ }^{3}$ Department of Industrial Engineering, College of Engineering, King Saud University, Riyadh, Saudi Arabia
}

Correspondence should be addressed to Adel Taha Abbas; atabbas1954@yahoo.com

Received 4 January 2017; Revised 5 February 2017; Accepted 7 February 2017; Published 6 March 2017

Academic Editor: Pavel Lejcek

Copyright (C) 2017 Adel Taha Abbas et al. This is an open access article distributed under the Creative Commons Attribution License, which permits unrestricted use, distribution, and reproduction in any medium, provided the original work is properly cited.

Solid state recycling through hot extrusion is a promising technique to recycle machining chips without remelting. Furthermore, equal channel angular pressing (ECAP) technique coupled with the extruded recycled billet is introduced to enhance the mechanical properties of recycled samples. In this paper, the surface roughness of solid state recycled aluminum alloy 6061 turning chips was investigated. Aluminum chips were cold compacted and hot extruded under an extrusion ratio (ER) of 5.2 at an extrusion temperature (ET) of $425^{\circ} \mathrm{C}$. In order to improve the properties of the extruded samples, they were subjected to ECAP up to three passes at room temperature using an ECAP die with a channel die angle $(\boldsymbol{\Phi})$ of $90^{\circ}$. Surface roughness $\left(R_{a}\right.$ and $\left.R_{z}\right)$ of the processed recycled billets machined by turning was investigated. Box-Behnken experimental design was used to investigate the effect of three machining parameters (cutting speed, feed rate, and depth of cut) on the surface roughness of the machined specimens for four materials conditions, namely, extruded billet and postextrusion ECAP processed billets to one, two, and three passes. Quadratic models were developed to relate the machining parameters to surface roughness, and a multiobjective optimization scheme was conducted to maximize material removal rate while maintaining the roughness below a preset practical value.

\section{Introduction}

In order to reduce energy consumption and $\mathrm{CO}_{2}$ emissions in manufacturing processes, recycling of wastes became very important. The main methods used for scrap recycling are conventional and solid state recycling [1]. The conventional recycling, which involves remelting of scrap, has many disadvantages such as high energy consumption, high production and labor cost, and large number of operations. Furthermore, in case of aluminum chips recycling, the losses are about $50 \%$ of the recycled scrap due to high surface area to volume ratio of the chips and contamination with machining oils $[2,3]$. The need for a recycling method in which the scrap can be recycled without remelting to avoid the disadvantages associated with the conventional method was the motivation of many recent investigations [1,4-7] of solid state recycling techniques. It was found that recycling of aluminum alloys chips by solid state method through hot extrusion can produce approximately fully dense products [4]. Moreover, about $95 \%$ of the primary material can be used by avoiding metal loss during the remelting process [4]. Furthermore, solid state recycling process can be applied to produce finished or semifinished products directly [5-7]. In order to improve the mechanical properties of the extruded recycled billets, it can be subjected to severe plastic deformation to refine and homogenize the grain structure. Recently, several studies on solid state recycling of machining chips through severe plastic deformation (SPD) have been conducted [8-10]. SPD techniques induce remarkably high strains that are capable of refining bulk materials with coarse grain structures.

Equal channel angular pressing (ECAP) technique being the most prominent of SPD techniques has been widely used 
for producing ultra-fine-grained (UFG) metals and alloys. ECAP involves pressing the sample in a die having intersecting equal channels. The deformation is mainly carried out by simple shear while the cross-section is maintained. This means that the samples can be repeatedly pressed to accumulate large amount of plastic strain that is capable of breaking down the coarse grains into submicron grains. During deformation the grain develop subgrains with low angle boundaries along with high dislocation density. Further deformation causes the subgrains to develop into grains with high angle boundaries. The associated enhancement in mechanical properties has been demonstrated in many previous works [11-15].

Abbas et al. [16] investigated the surface roughness for five starting material conditions (annealed and ECAP processed to $1,2,3$, and 4 passes) for 1050 aluminum alloy. Quadratic models that related the four surface roughness $\left(R_{a}, R_{q}, R_{t}\right.$ and $R_{z}$ ) values to the three cutting parameters (cutting speed, feed rate, and depth of cut) were developed, while the fourth parameter (number of ECAP passes) was considered as categorical factor. The results showed that optimum (minimum) surface roughness was achieved at minimum depth of cut $(0.15 \mathrm{~mm})$ and minimum feed rate $(0.05 \mathrm{~mm} / \mathrm{rev})$ with slightly different cutting speeds that ranged between $193 \mathrm{~m} / \mathrm{min}$ for $R_{z}$ and $207.5 \mathrm{~m} / \mathrm{min}$ for $R_{a}$. The surface quality of the ECAP processed material was found to be much superior compared to its annealed counterpart, for the same cutting conditions.

Khamis et al. [17] investigated the mechanical properties of recycled AA6061 chip that was produced from high speed milling. ANOVA analysis showed that holding compaction time was the most influential parameter whereas chip size had the least effect. The desirability function concluded that longer holding time and more precompaction with large chip size will give the higher tensile strength (UTS) value.

Chan and Lajis [18] investigated the cold compaction of aluminum 6061 chips to conclude that the optimum pressure is $650 \mathrm{MPa}$. The associated density was reported to be about $98.5 \%$ of the reference sample without going into any sintering process. They concluded that pressureless sintering breaks the interlocking which increases the gaps that increase the overall volume which causes the density of the compressed specimen to be reduced. They concluded that the mechanical properties of the compacted samples are still lower than their cast counterpart.

Duflou et al. [19] investigated the solid state recycling techniques of aluminum alloys directly from production scrap. They used three different techniques, namely, hot extrusion, screw extrusion, and spark plasma sintering (SPS), and compared them with the conventional remelting route for reference. It was concluded that aluminum recycling reduced the environmental impact with preferential material and energy savings. An overall impact reduction with a factor of 2 for the SPS route and 3-4 for the extrusion routes was reported.

Chiba and Yoshimura [7] investigated the solid state recycling of $\mathrm{Al}-\mathrm{Si}$ alloy chips produced by milling and turning. Cold compaction into columnar billets that were subsequently profile-extruded into equilateral c-channels at
TABLE 1: Chemical composition of Aluminum Alloy AA6061.

\begin{tabular}{lcccccc}
\hline $\mathrm{Si}$ & $\mathrm{Mg}$ & $\mathrm{Fe}$ & $\mathrm{Cu}$ & $\mathrm{Mn}$ & Others & $\mathrm{Al}$ \\
\hline 0.8 & 0.85 & 0.48 & 0.26 & 0.051 & 0.329 & Balance \\
\hline
\end{tabular}

$600 \mathrm{~K}$, under extrusion ratios of 10 and 18 , was performed. Uniaxial tensile tests showed that the dense recycled material had a higher ductility than the original ingot, with a reduction of around $30 \%$ in the ultimate tensile strength. The material recycled from the turning chips exhibited insufficient bonding, as compared to that recycled from the milling chips under the same conditions, thereby resulting in inferior mechanical properties.

The objective of the current work is to investigate the surface roughness, as an indicator of product surface quality, of solid state recycled 6061 aluminum chips produced by dry turning. Solid state recycling involved three steps comprising cold compaction followed by hot extrusion and finally for improving mechanical properties the extruded billet was further deformed in an equal channel die up to one, two, and three passes. Cutting parameters, namely, depth of cut, feed rate, and cutting speed, will be the process variables considered in a quadratic model that relates surface roughness to experimental machining conditions.

\section{Materials and Methods}

The material used in this paper is aluminum alloy AA6061 (as-received extruded rod). Table 1 presents the chemical composition of this alloy. The machined chips were prepared by dry turning of the as-received rod under the following cutting conditions: cutting speed of $88 \mathrm{~m} / \mathrm{min}(V)$, feed of $1 \mathrm{~mm} / \mathrm{rev}\left(f_{r}\right)$, and depth of cut of $1 \mathrm{~mm}(d)$. The chips were placed in a die with a diameter of $25 \mathrm{~mm}$, cold compacted at room temperature, and then hot extruded at a temperature of $425^{\circ} \mathrm{C}$ with an extrusion ratio of 5.2. In order to improve the properties of the extruded samples, the samples were subjected to ECAP process up to three passes at room temperature using an ECAP die with a channel die angle $(\boldsymbol{\Phi})$ equal $90^{\circ}$.

The microstructure of as-received and extruded specimens was examined using optical microscopy on Zeiss Axio Imager. On the other hand, after ECAP, the microstructure was examined using FEI INSPECT S50 scanning electron microscope (SEM), because of the expected fine microstructure. Metallographic specimens were ground, polished, and etched using kellers reagent. Vickers microhardness was measured under an applied loading of $100 \mathrm{gf}$ and a dwell time of $15 \mathrm{sec}$ at room temperature using Buehler Micromet 5100 device. The tensile test was conducted at room temperature using LR300 K ( $300 \mathrm{kN})$ universal testing machine. Tensile tests were performed at an initial strain rate of $8.33 \times 10^{-4} \mathrm{~s}^{-1}$ at room temperature. Tensile test specimens were fabricated parallel to extrusion and ECAP direction in accordance with ASTM-B557-06.

The final processed billets were machined using Emco Concept Turn $45 \mathrm{CNC}$ lathe. This machine is equipped with Sinumeric $840-\mathrm{D}$. All test runs were done using CNC part 


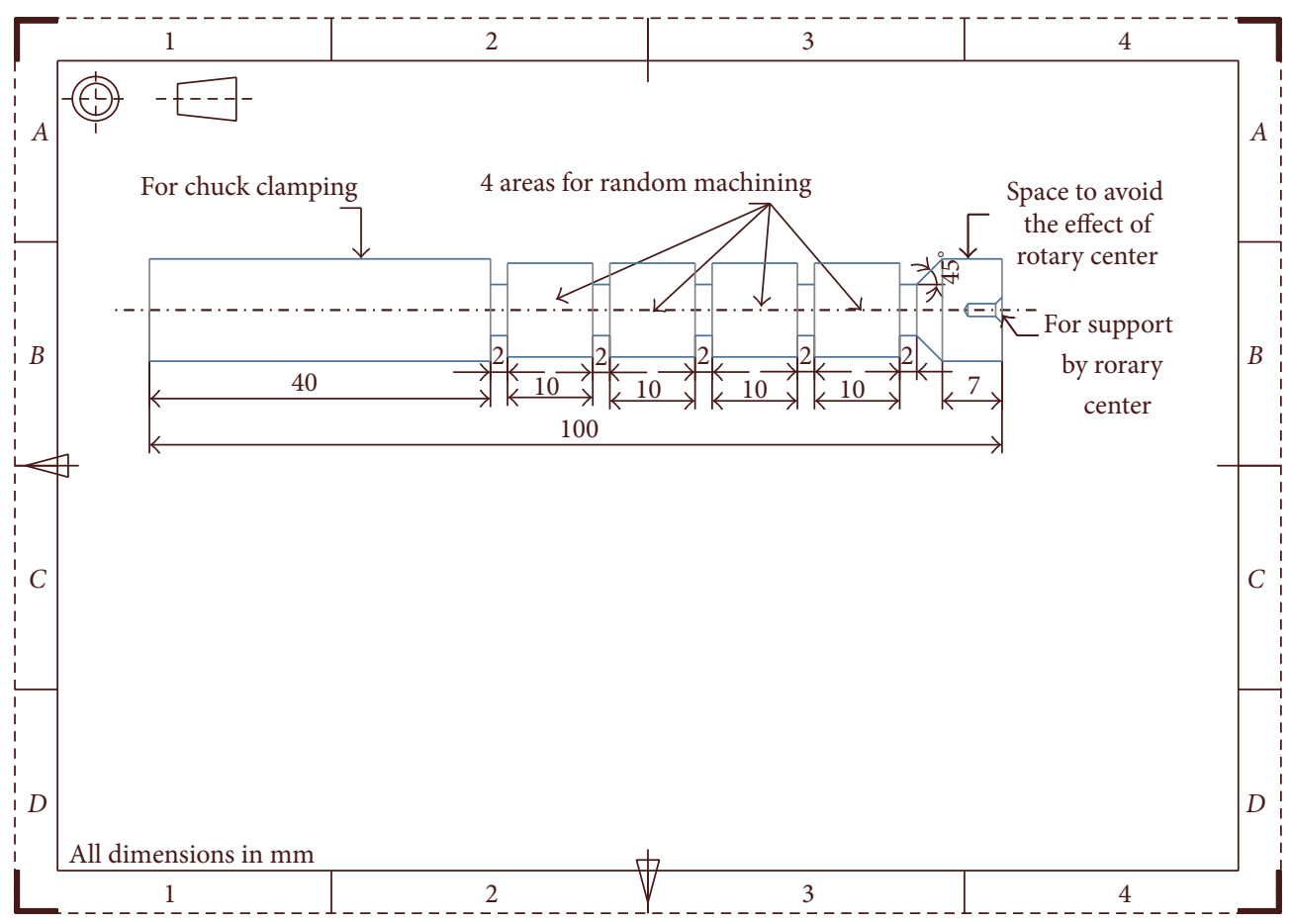

FIGURE 1: Test specimen drawing.

TABLE 2: The cutting parameters and their levels used in the Box-Behnken design.

\begin{tabular}{lccccc}
\hline Designation & Process parameter & Level 1 & Level 2 & Level 3 & Level 4 \\
\hline$A$ & $V$ & 100 & 150 & 200 & - \\
$B$ & $d$ & 0.10 & 0.25 & 0.40 & - \\
$C$ & $f_{r}$ & 0.012 & 0.081 & 0.15 & - \\
$D$ & Specimen condition & No ECAP (1) & One pass ECAP (2) & Two passes ECAP (3) & Three passes ECAP (4) \\
\hline
\end{tabular}

program. The specifications for tool holder and insert are SVJCL2020K16 and VCGT160404 FN-ALU, respectively. The clearance angle, cutting edge angle, and nose radius are maintained at $5^{\circ}, 35^{\circ}$ and $0.4 \mathrm{~mm}$, respectively. All cutting parameters were controlled via CNC part program and all the experiments were conducted in wet conditions. The surface roughness was evaluated using surface roughness tester TESA. The test specimens had an initial diameter of $12 \mathrm{~mm}$ and a length of $100 \mathrm{~mm}$. The test specimens were divided into six areas. The first area with a length of $40 \mathrm{~mm}$ was used for chuck clamping, and the other four areas with $10 \mathrm{~mm}$ for each and separated by a groove of $2 \mathrm{~mm}$ were used for random machining with different cutting parameters and the last area was used for centering. The test specimen drawing is shown in Figure 1. The test specimens had four different starting conditions: hot extruded at $425^{\circ} \mathrm{C}$ and ECAP up to three passes. The cutting parameters and values of surface roughness $\left(R_{a}\right.$, and $\left.R_{z}\right)$ and the calculated material removal rate were recorded in the Appendix. Where $R_{a}$ is the arithmetic average deviation of the assessed profile $(\mu \mathrm{m})$ and $R_{z}$ is the average maximum height of the profile $(\mu \mathrm{m})$.

\section{Design of Experiments}

Box-Behnken design is one of response surface methodology (RSM) designs that is used extensively in studying and optimizing surface roughness of different machining processes through several publications [20-23]. RSM is a collection of statistical and mathematical techniques used to optimize a considered output variable, or response (represented in the model by the dependent variable) that is influenced by a set of controllable input variables, or factors (represented in the model by the independent variables) [24].

The Box-Behnken design was first introduced in 1960 by Box and Behnken [24]. In this research a rotatable BoxBehnken design consisting of 60 experiments was built including four factors, namely, cutting speed, depth of cut, feed rate, and specimen condition. Table 2 summarizes the studied factors and their levels. The specimen condition was treated as a categorical variable, while the other factors were treated as continuous variables. The Appendix illustrates the full list of experiments with measured response values $\left(R_{a}\right.$ and $R_{z}$ ) in micrometers. 


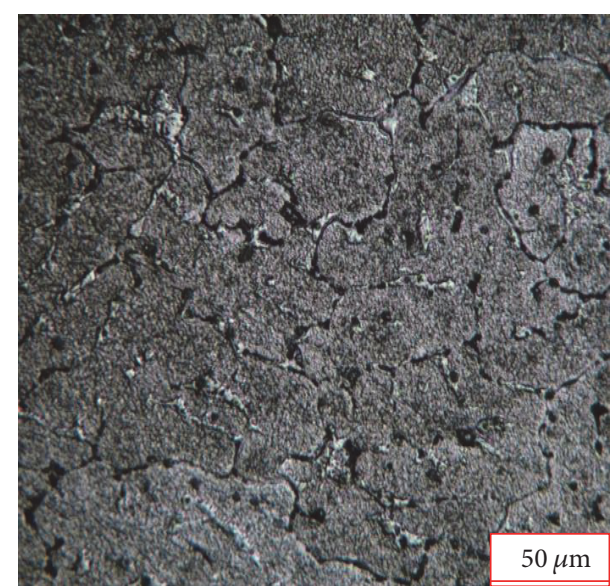

(a)

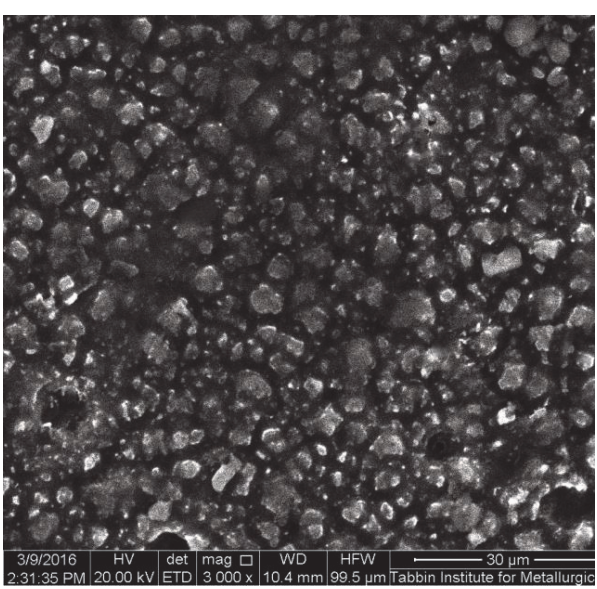

(c)

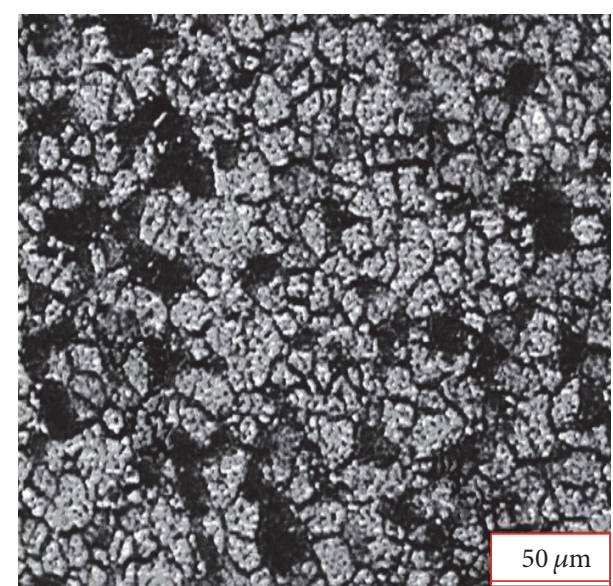

(b)

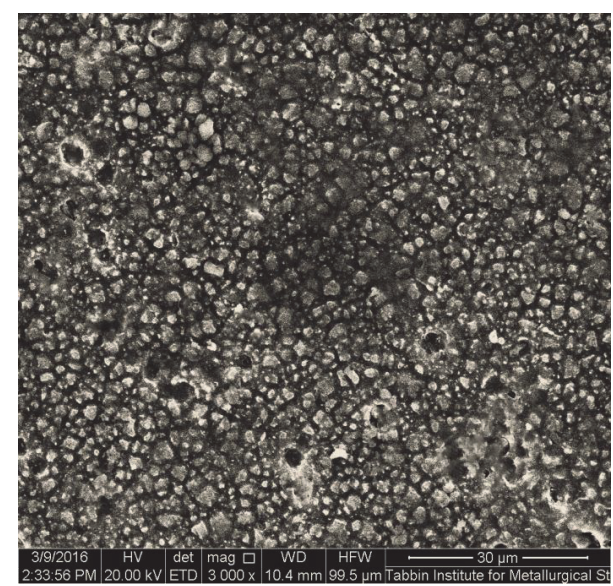

(d)

FIgURE 2: Microstructure of (a) as-received, (b) ET $=425^{\circ} \mathrm{C}$, (c) ECAP-1, and (d) ECAP-3.

\section{Results and Discussions}

The microstructures of the as-received sample are shown in Figure 2(a). It consists of coarse-grained structure with grain size of about $48 \mu \mathrm{m}$. On the other hand, the microstructure of the hot extruded specimen consists of fine grains of about $13.5 \mu \mathrm{m}$, as shown in Figure 2(b). The finer grained microstructure is caused by severe plastic strain imposed during the recycling processes and the positive effect of chip boundaries which can act as barriers between grains to prevent grain growth [25-28]. The decrease in grain size was congruent with previous work done by Haase et al. [25] where the grain size of the as-received AA-6060 alloy was $385 \mu \mathrm{m}$, while it was $31.8 \mu \mathrm{m}$ for the hot extruded chips at $450^{\circ} \mathrm{C}$. Also, Selmy et al. $[26,27]$ recycled AA6061 chips through hot extrusion; the grain size was $48 \mu \mathrm{m}$ for as-received samples while it was 15.8 and $10.9 \mu \mathrm{m}$ for the recycled samples produced by hot extrusion at 500 and $350^{\circ} \mathrm{C}$, respectively. Moreover in previous work by $\mathrm{Hu}$ et al. [28], the Mg chips were classified into three different groups based on its size. The $\mathrm{Mg}$ chips were cold compacted and followed by hot extrusion at $400^{\circ} \mathrm{C}$. The grain size of the asreceived sample was $200 \mu \mathrm{m}$, while it was 22,25 , and $11 \mu \mathrm{m}$
TABLE 3: Effect of ECAP process on the Solid Sate Recycled Aluminum Alloy 6061 chips after Extrusion temperature $425^{\circ} \mathrm{C}$.

\begin{tabular}{lcccc}
\hline Description & $\mathrm{ET}=425^{\circ} \mathrm{C}$ & ECAP-1 & ECAP-2 & ECAP-3 \\
\hline Relative density \% & 96.4 & 99 & 99.8 & 99.8 \\
Microhardness, Vickers & 43 & 76.25 & 80.75 & 82.75 \\
Ultimate T. Strength, MPa & 114.7 & 198 & 230.8 & 306.4 \\
Elongation to failure, $\mathrm{mm}$ & 9.85 & 10.3 & 11.2 & 12.3 \\
Grain size, $\mu \mathrm{m}$ & 13.5 & 5.22 & 4 & 3.25 \\
\hline
\end{tabular}

for the three different groups of $\mathrm{Mg}$ chips recycled by hot extrusion. SEM micrographs of ECAPed samples after 1 and 3 passes are shown in Figures 2(c) and 2(d), respectively. It is obvious that additional grain refinement is exhibited with increasing number of ECAP passes. The grain size for the ECAPed samples processed to 1 and 3 passes is 5 and $3.25 \mu \mathrm{m}$, respectively.

Table 3 presents the relative density, microhardness, and ultimate tensile strength; elongation to failure and grain size of the solid state recycled aluminum alloy 6061 chips after extrusion and after the extruded billet were processed by 
TABLE 4: Quadratic models for $R_{a}$, and $R_{z}$.

\begin{tabular}{lll}
\hline Response & $D$ & Equation \\
\hline \multirow{2}{*}{$R_{a}$} & 1 & $1.334-0.00971 A-2.101 B-9.972 C+0.000036 A^{2}+4.468 B^{2}+120.55 C^{2}+4.56 B * C$ \\
& 2 & $1.191-0.00971 A-2.101 B-9.972 C+0.000036 A^{2}+4.468 B^{2}+120.55 C^{2}+4.56 B * C$ \\
& 3 & $1.153-0.00971 A-2.101 B-9.972 C+0.000036 A^{2}+4.468 B^{2}+120.55 C^{2}+4.56 B * C$ \\
& 4 & $1.130-0.00971 A-2.101 B-9.972 C+0.000036 A^{2}+4.468 B^{2}+120.55 C^{2}+4.56 B * C$ \\
$R_{z}$ & 1 & $7.04-0.01399 A-27.97 B-51.62 C+36.90 B^{2}+496.6 C^{2}+0.0771 A * B+0.1211 A * C$ \\
& 2 & $5.77-0.01399 A-27.97 B-51.62 C+36.90 B^{2}+496.6 C^{2}+0.0771 A * B+0.1211 A * C$ \\
& 3 & $5.57-0.01399 A-27.97 B-51.62 C+36.90 B^{2}+496.6 C^{2}+0.0771 A * B+0.1211 A * C$ \\
& 4 & $5.45-0.01399 A-27.97 B-51.62 C+36.90 B^{2}+496.6 C^{2}+0.0771 A * B+0.1211 A * C$ \\
\hline
\end{tabular}

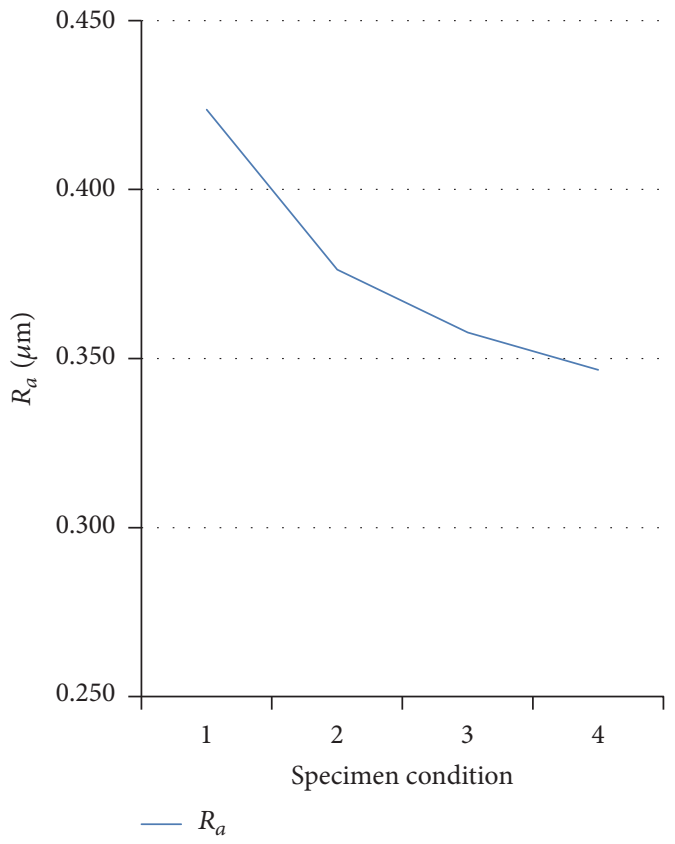

FIgURE 3: Surface roughness, $R_{a}(\mu \mathrm{m})$ versus specimen condition.

ECAP to one, two, and three passes. The values are presented in Table 3 for the properties of the solid state recycled billets point towards the successfulness of recycling the chips into a consolidated bulk materials via cold compaction, followed by hot extrusion and finally ECAP. Table 3 shows the influence of number of ECAP passes on the microhardness of recycled samples. The microhardness has increased from $43 \mathrm{HV}$ after extrusion to about $83 \mathrm{HV}$ when extrusion was coupled with ECAP to 3 passes, which means that the hardness is almost doubled. Also, the ultimate tensile strength has increased from 115 to $307 \mathrm{MPa}$, which means that the tensile strength is almost tripled. This remarkable increase in mechanical strength is mainly due to the high dislocation density and the grain refinement associated with severe deformation accompanied with ECAP. Room temperature ECAP deformation has also resulted in improving the relative density. The increase in mechanical strength is expected to have significant effect on surface roughness.

Figures 3 and 4 show the variation of both $R_{a}$ and $R_{z}$ versus the specimen condition, respectively. The roughness

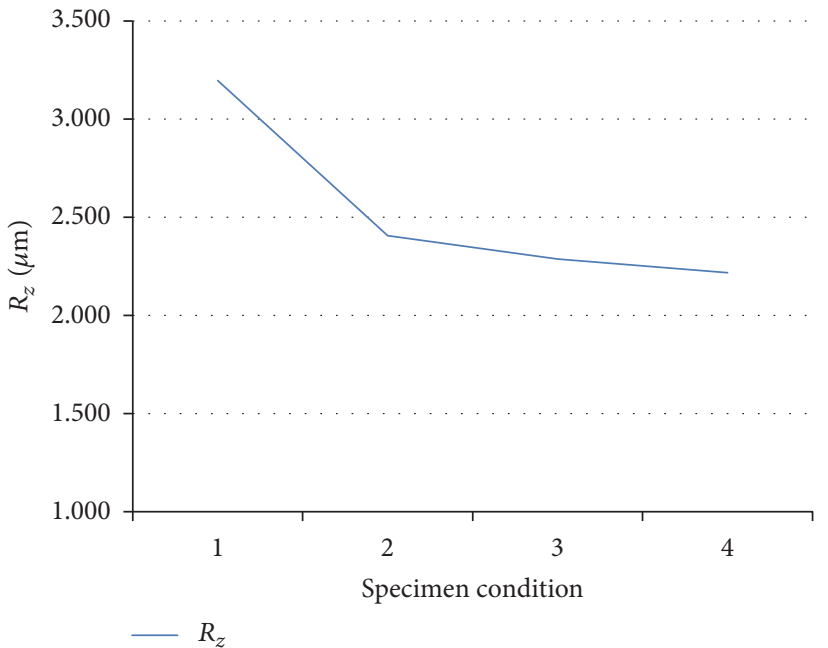

FIGURE 4: Surface roughness, $R_{z}(\mu \mathrm{m})$ versus specimen condition.

was measured at the same machining conditions (cutting speed of $150 \mathrm{~m} / \mathrm{min}$, depth of cut of $0.25 \mathrm{~mm}$, and feed rate of $0.081 \mathrm{~mm} / \mathrm{rev}$.) which embrace the center point of the BoxBehnken design. The figures illustrate that the roughness values of studied specimens decrease with the number of ECAP passes. The change between extruded specimens (no ECAP) and one pass ECAP specimens is significantly high. Extra passes reduce the value of surface roughness but with less slope.

A quadratic model of the form given in (1) was fitted to the data using Minitab 17 software depending on the BoxBehnken design. Stepwise technique was used to reduce the model into significant terms only. Stepwise is an automated technique that adds terms to the model one by one. The added term is kept in the model if it has a significant effect ( $p$ value $<0.05)$; otherwise, it is removed. The process is repeated until the model includes only all of the significant term.

$$
y=\beta_{o}+\sum_{i=1}^{k} \beta_{i} X_{i}+\sum_{i=1}^{k} \beta_{i i} X_{i}^{2}+\sum \sum_{i<j} \beta_{i j} X_{i} X_{j}
$$

where $\beta_{o}$ is the constant term, $\beta_{i}$ represents the linear effects, $\beta_{i i}$ represents the pure quadratic effects, and $\beta_{i j}$ represents the second level interaction effects. Table 4 illustrates the 


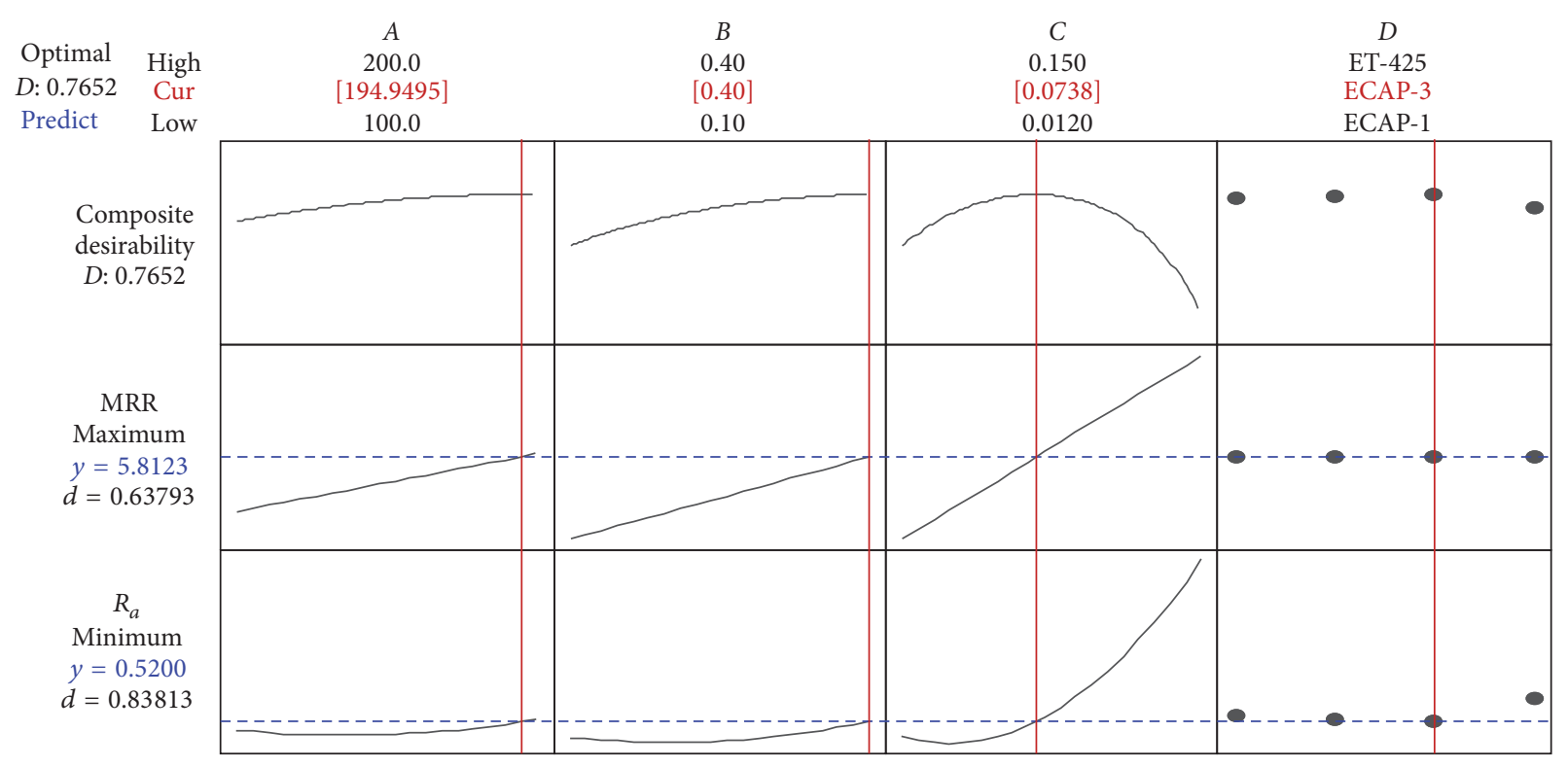

FIGURE 5: Optimization plot for $R_{a}$.

quadratic models developed for $R_{a}$ and $R_{z}$. The specimen condition (factor $D$ ) and its significant interactions are not included in the equation since it is treated as a categorical factor as mentioned before. The adequacy of the quadratic models was tested through calculating the coefficient of determination. Adjusted $R$-squared and predicted $R$-squared were calculated as $99 \%$ and $98 \%$ for $R_{a}$, respectively, and 95\% and $93 \%$ for $R_{z}$, respectively. Anderson-Darling test was conducted to check the normality of residuals with a result of $p$ value $=0.695$ for $R_{a}$ and 0.169 for $R_{z}$ assuming normally distributed residuals. The null hypothesis of such a test is that the data are normal and a $p$ value $<0.05$ proves nonnormality.

Material removal rate (MRR) was calculated for each run using (2), where $V$ is surface cutting speed ( $\mathrm{m} / \mathrm{min}$.), $f_{r}$ is feed rate $(\mathrm{mm} / \mathrm{rev}$.$) , and d$ is depth of cut $(\mathrm{mm})$. Optimization process was run using the desirability function approach to maximize MRR while maintaining $R_{a}$ below $0.8 \mu \mathrm{m}$, which is practically adopted in industry.

$$
\operatorname{MRR}=V * d * f_{r}
$$

Desirability function approach was used to estimate the values of studied process parameters that maximize the MRR keeping the $R_{a}$ at levels not exceeding a practical value of $0.8 \mu \mathrm{m}$. The optimization plot, illustrated in Figure 5, shows that an optimum MRR of $5.812 \mathrm{~cm}^{3} / \mathrm{min}$ with $R_{a}$ of $0.520 \mu \mathrm{m}$ is obtained at cutting speed of $195 \mathrm{~m} / \mathrm{min}$., depth of cut of $0.4 \mathrm{~mm}$, and feed rate of $0.073 \mathrm{~mm} / \mathrm{rev}$, for three-pass ECAP alloy (specimen condition 4 ).

ANOVA was used to examine the effect of studied factors, in both linear and quadratic forms, and their interactions for their significance in the model. The results for $R_{a}$, illustrated in Table 5, show that all factors has significant effect on $R_{a}$ with their both linear and quadratic terms. The feed rate, by far, had the greatest influence on the surface roughness in both its linear and quadratic terms.

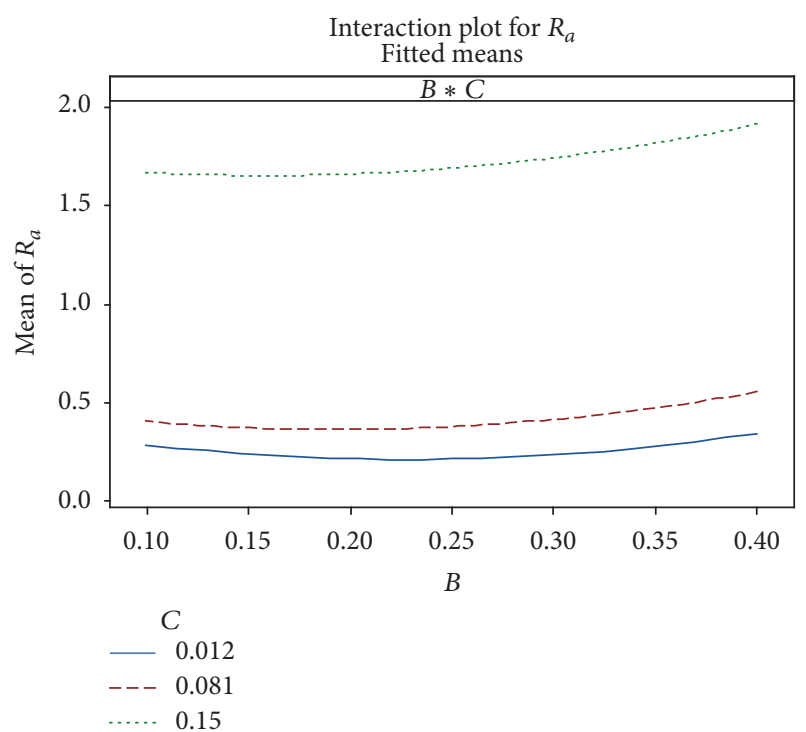

FiguRE 6: Interaction plot of depth of cut and feed rate for $R_{a}$.

Figure 6 shows the interaction plot for depth of cut and feed rate which is the only significant interaction affecting $R_{a}$. Although the interaction is significant, it has little effect on the variation of $R_{a}$ which is illustrated by almost parallel curves in the plot. The same pattern is illustrated in the response surface given in Figure 7 . The ANOVA results for $R_{z}$ showed the same patterns except that the significant interactions are cutting speed/depth of cut and cutting speed/feed rate.

To validate the model, extra 12 experimental runs were conducted. Three cutting conditions were selected for the four starting specimen conditions (ET- $425^{\circ} \mathrm{C}$, ECAP-1, ECAP-2, and ECAP-3). Two among these three conditions 
TABLE 5: ANOVA results for $R_{a}$.

\begin{tabular}{|c|c|c|c|c|c|}
\hline Source & $\mathrm{DF}$ & Adj SS & Adj MS & $F$-value & $p$ value \\
\hline Model & 10 & 23.0431 & 2.3043 & 475.18 & 0 \\
\hline Linear & 6 & 18.0698 & 3.0116 & 621.05 & 0 \\
\hline$A$ & 1 & 0.0761 & 0.0761 & 15.7 & 0 \\
\hline$B$ & 1 & 0.1812 & 0.1812 & 37.37 & 0 \\
\hline C & 1 & 17.436 & 17.436 & 3595.57 & 0 \\
\hline$D$ & 3 & 0.3765 & 0.1255 & 25.88 & 0 \\
\hline Square & 3 & 4.9376 & 1.6459 & 339.4 & 0 \\
\hline$A * A$ & 1 & 0.1172 & 0.1172 & 24.17 & 0 \\
\hline$B * B$ & 1 & 0.1492 & 0.1492 & 30.77 & 0 \\
\hline$C * C$ & 1 & 4.8654 & 4.8654 & 1003.32 & 0 \\
\hline 2-way interaction & 1 & 0.0356 & 0.0356 & 7.35 & 0.009 \\
\hline$B * C$ & 1 & 0.0356 & 0.0356 & 7.35 & 0.009 \\
\hline Error & 49 & 0.2376 & 0.0048 & & \\
\hline Lack-of-fit & 41 & 0.2373 & 0.0058 & 169.84 & 0 \\
\hline Pure error & 8 & 0.0003 & 0 & & \\
\hline Total & 59 & 23.2807 & & & \\
\hline
\end{tabular}

TABLE 6: Extra runs for valediction and verification of the predicted equations in Table 4.

\begin{tabular}{lccccc}
\hline Run Order & Condition & Surface Speed $(\mathrm{m} / \mathrm{min})$ & Depth of cut $(\mathrm{mm})$ & Feed $(\mathrm{mm} / \mathrm{rev})$ & $\begin{array}{c}R_{a},(\mu \mathrm{m}) \\
\text { Experimental }\end{array}$ \\
\hline 1 & ET-425 & 125 & 0.325 & 0.125 & 1.378 \\
2 & ET-425 & 195 & 0.400 & 0.073 & 0.758 \\
3 & ET-425 & 250 & 0.500 & 0.20 & 4.88 \\
4 & ECAP-1 & 125 & 0.325 & 0.125 & 0.732 \\
5 & ECAP-1 & 195 & 0.400 & 0.073 & 1.267 \\
6 & ECAP-1 & 250 & 0.500 & 0.20 & 0.654 \\
7 & ECAP-2 & 125 & 0.325 & 0.125 & 4.589 \\
8 & ECAP-2 & 195 & 0.400 & 0.073 & 1.150 \\
9 & ECAP-2 & 250 & 0.500 & 0.20 & 0.610 \\
10 & ECAP-3 & 125 & 0.325 & 0.125 & 4.364 \\
11 & ECAP-3 & 195 & 0.400 & 0.073 & 0.113 \\
12 & ECAP-3 & 250 & 0.500 & 0.20 & 4.303 \\
\hline
\end{tabular}

were taken within the data range, one of which was the predicted optimum condition. The third condition was taken out of the data range. For all these 12 conditions, the measured surface roughness values were compared to the predicted ones as shown in Table 6. Figure 8 shows a scatter plot for both measured and predicted values. It is clear from the figure that the relation between them is linear with calculated $R^{2}$ of 0.99. It is worth mentioning that the machining parameters that corresponded to the optimum condition of $R_{a}$ and MMR (cutting speed of $195 \mathrm{~m} / \mathrm{min}$., depth of cut of $0.40 \mathrm{~mm}$, and feed rate of $0.073 \mathrm{~mm} / \mathrm{rev}$ ) yielded an experimental value of $R_{a}$ of 0.502 compared to the predicted value of 0.520 which exhibits less than $5 \%$ error.

\section{Conclusion}

Solid state recycling of 6061 aluminum chips was conducted. The final bulk material was produced via cold compaction followed by hot extrusion and finally equal channel angular pressing for one, two, and three passes. Mechanical properties revealed the effectiveness of the compaction route in producing a densified product. Surface roughness was measured for four materials conditions comprising as extruded sample as well as samples extruded and ECAP processed to one, two, and three passes. The sample ECAP processed to three passes exhibited the highest hardness and consequently gave the lowest surface roughness. Box-Behnken experimental design was used to investigate the effect of three machining parameters (cutting speed, feed rate, and depth of cut) on the surface roughness of the machined specimens. A quadratic model was developed that related $R_{a}$ and $R_{z}$ to the machining parameters, with the material condition being a categorical variable. Feed rate was concluded to be the most influential parameter affecting surface roughness. Multiobjective optimization results showed that the minimum value of MRR was calculated as $5.812 \mathrm{~cm}^{3} / \mathrm{min}$ for surface roughness 


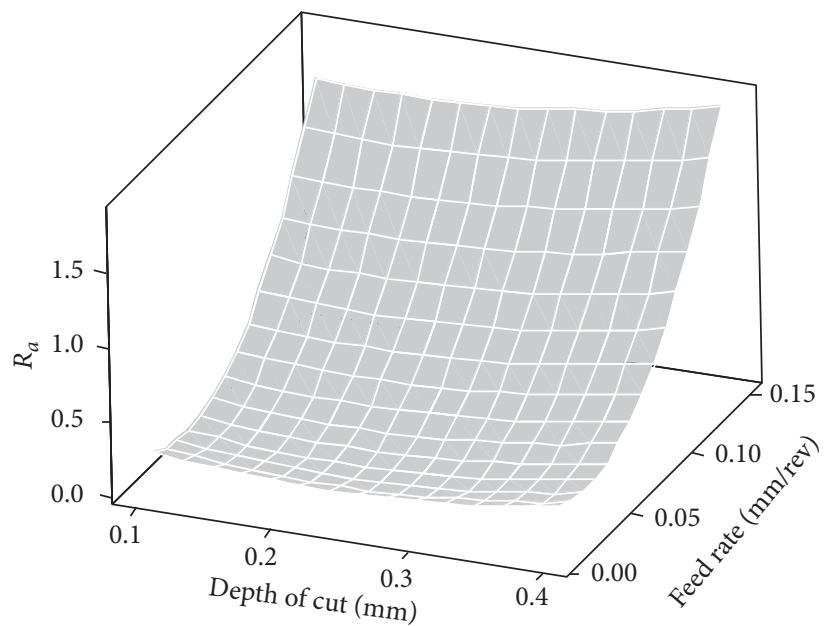

$$
\begin{array}{cc}
\text { Hold values } \\
A & 150 \\
D & \text { ECAP-3 }
\end{array}
$$

FIGURE 7: Response surface plot for $R_{a}$ versus depth of cut and feed rate at a mean cutting speed of $150 \mathrm{~m} / \mathrm{min}$.

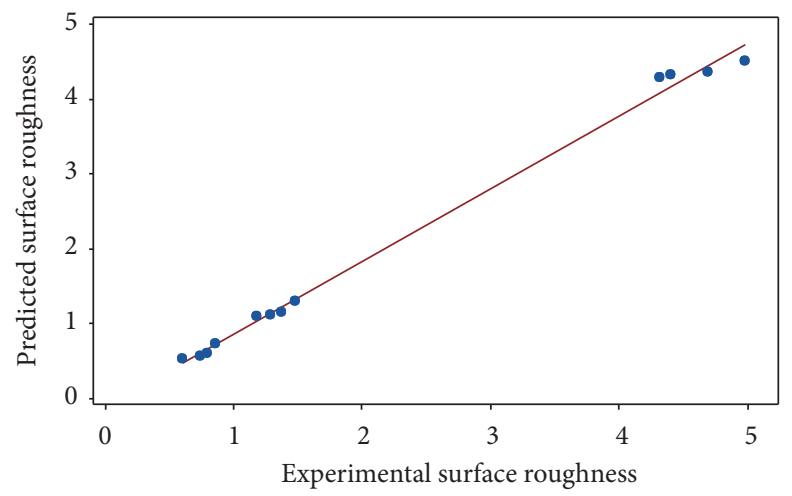

Figure 8: Scatter plot for the predicted versus experimental $R_{a}$ values for the (12) validation runs.

of $0.520 \mu \mathrm{m}$ at cutting speed of $195 \mathrm{~m} / \mathrm{min}$., depth of cut of $0.40 \mathrm{~mm}$, and feed rate of $0.073 \mathrm{~mm} / \mathrm{rev}$. (12) validation experimental tests were conducted with three new cutting conditions. The difference between the experimental and predicted values of $R_{a}$ for the new 12 experiments was in the range of $3-10 \%$, which proves the applicability of the developed models.

\section{Appendix}

See Table 7.

\section{Nomenclature}

\section{$d: \quad$ Depth of cut, mm}

ECAP: Equal channel angular pressing

ER: Extrusion ratio
ET: $\quad$ Extrusion temperature, ${ }^{\circ} \mathrm{C}$

Ф: $\quad$ Channel die angle

$f_{r}: \quad$ Feed rate, $\mathrm{mm} / \mathrm{rev}$

MRR: Material removal rate, $\mathrm{cm}^{3} / \mathrm{min}$

$N$ : $\quad$ Spindle speed, $\mathrm{rpm}$

$R_{a}$ : The arithmetic average deviation of the assessed profile, $\mu \mathrm{m}$

$R_{z}$ : The average maximum height of the profile, $\mu \mathrm{m}$

Status: (1) for extrude temperature $425^{\circ} \mathrm{C}$, (2) one pass ECAP, (3) two passes ECAP, and (4) Three passes ECAP

$V: \quad$ Surface speed, $\mathrm{meter} / \mathrm{min}$.

\section{Competing Interests}

The authors declare that they have no competing interests. 


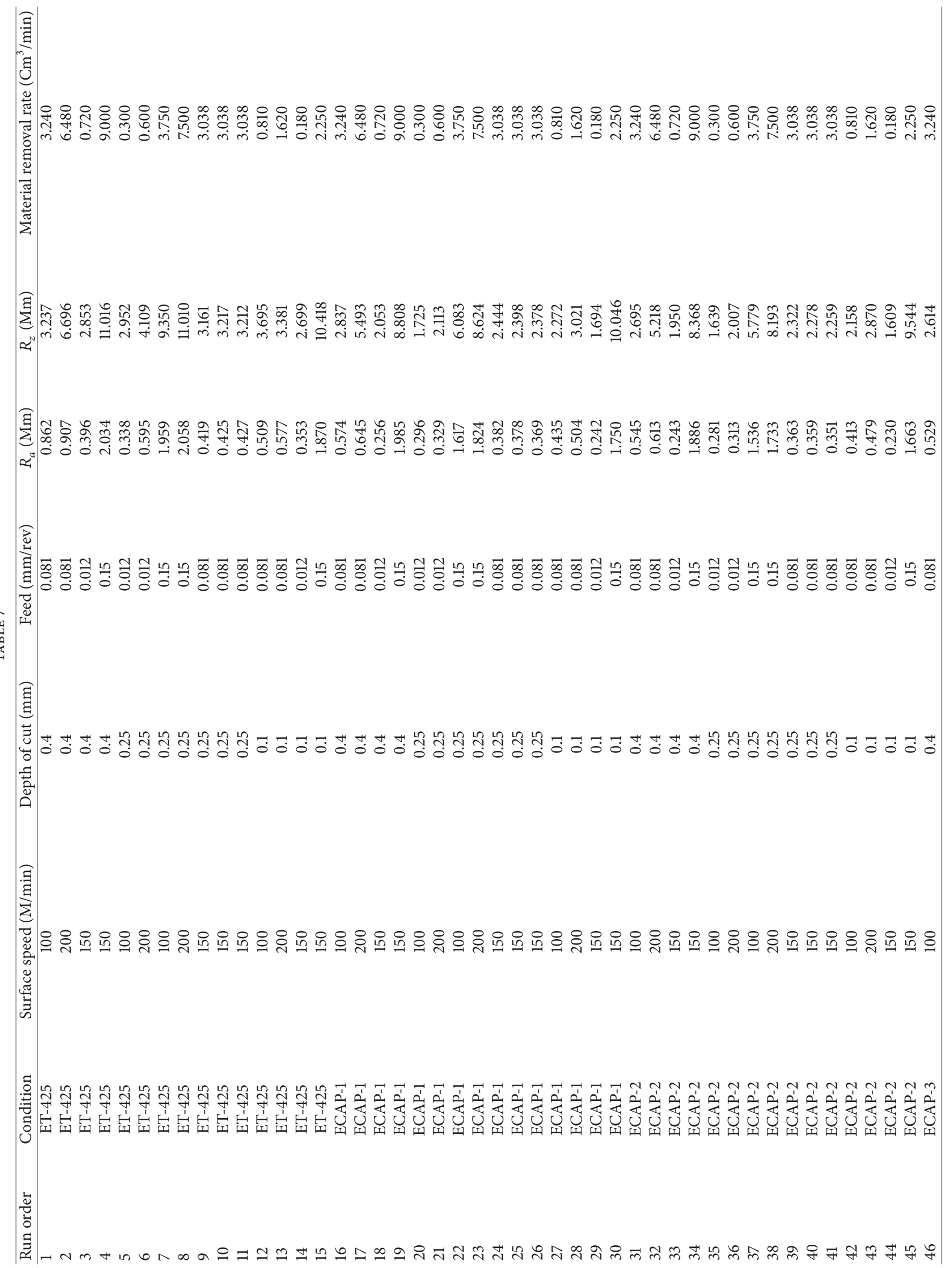




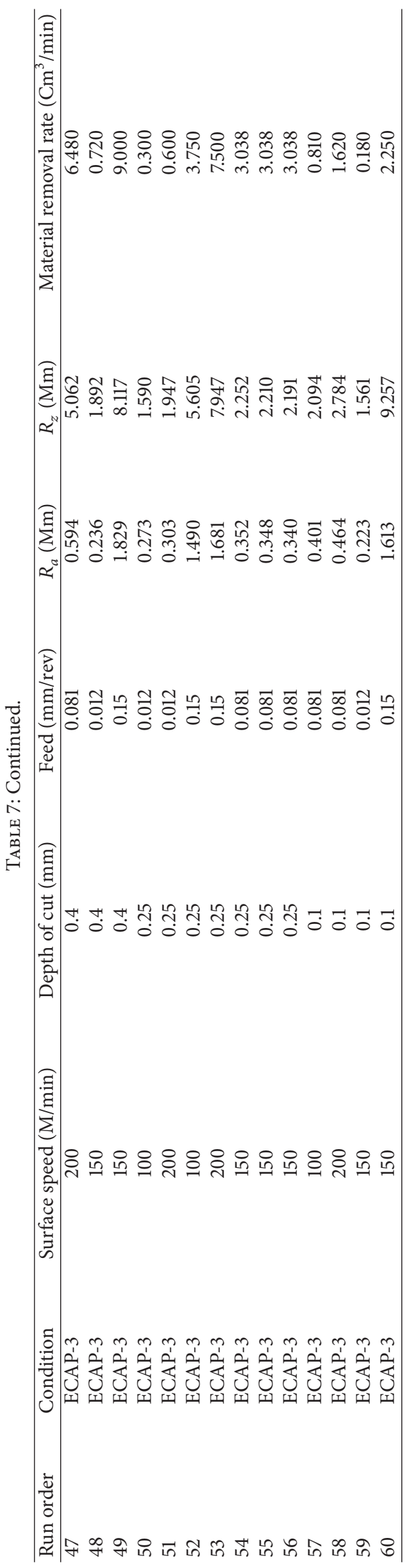




\section{Acknowledgments}

This Project was supported by King Saud University, Deanship of Scientific Research, College of Engineering Research Center. Authors would like to thank Twasol Research Excellence Program (TRE Program), King Saud University, Riyadh, Saudi Arabia, for support.

\section{References}

[1] A. E. Tekkaya, M. Schikorra, D. Becker, D. Biermann, N. Hammer, and K. Pantke, "Hot profile extrusion of AA-6060 aluminum chips," Journal of Materials Processing Technology, vol. 209, no. 7, pp. 3343-3350, 2009.

[2] J. Z. Gronostajski, J. W. Kaczmar, H. Marciniak, and A. Matuszak, "Production of composites from $\mathrm{Al}$ and $\mathrm{AlMg} 2$ alloy chips," Journal of Materials Processing Technology, vol. 77, no. 1-3, pp. 37-41, 1998.

[3] W. H. Macintosh, "Induction furnaces for melting secondary aluminium," Conservation and Recycling, vol. 6, no. 1-2, pp. 4148, 1983.

[4] J. Z. Gronostajski, H. Marciniak, and A. Matuszak, "Production of composites on the base of AlCu4 alloy chips," Journal of Materials Processing Technology, vol. 60, no. 1-4, pp. 719-722, 1996.

[5] M. Haase and A. E. Tekkaya, "Cold extrusion of hot extruded aluminum chips," Journal of Materials Processing Technology, vol. 217, pp. 356-367, 2015.

[6] W. Tang and A. P. Reynolds, "Production of wire via friction extrusion of aluminum alloy machining chips," Journal of Materials Processing Technology, vol. 210, no. 15, pp. 2231-2237, 2010.

[7] R. Chiba and M. Yoshimura, "Solid-state recycling of aluminium alloy swarf into c-channel by hot extrusion," Journal of Manufacturing Processes, vol. 17, pp. 1-8, 2015.

[8] T. Aida, N. Takatsuji, K. Matsuki, S. Kamado, and Y. Kojima, "Homogeneous consolidation process by ECAP for AZ31 cutting chips," Journal of Japan Institute of Light Metals, vol. 54, no. 11, pp. 532-537, 2004.

[9] T. Takahashj, Y. Kume, M. Kobashi, and N. Kanetake, "Solid state recycling of aluminum machined chip wastes by compressive torsion processing," Keikinzoku/Journal of Japan Institute of Light Metals, vol. 59, no. 7, pp. 354-358, 2009.

[10] T. Peng, Q. D. Wang, and J. B. Lin, "Microstructure and mechanical properties of $\mathrm{Mg}-10 \mathrm{Gd}-2 \mathrm{Y}-0.5 \mathrm{Zr}$ alloy recycled by cyclic extrusion compression," Materials Science and Engineering A, vol. 516, no. 1-2, pp. 23-30, 2009.

[11] E. A. El-Danaf, "Mechanical properties, microstructure and texture of single pass equal channel angular pressed 1050, 5083, 6082 and 7010 aluminum alloys with different dies," Materials and Design, vol. 32, no. 7, pp. 3838-3853, 2011.

[12] M. S. Soliman, E. A. El-Danaf, and A. A. Almajid, "Effect of equal-channel angular pressing process on properties of 1050 Al alloy," Materials and Manufacturing Processes, vol. 27, no. 7, pp. 746-750, 2012.

[13] M. Furukawa, Z. Horita, M. Nemoto, and T. G. Langdon, "The use of severe plastic deformation for microstructural control," Materials Science and Engineering A, vol. 324, no. 1-2, pp. 82-89, 2002.

[14] K. Nakashima, Z. Horita, M. Nemoto, and T. G. Langdon, "Influence of channel angle on the development of ultrafine grains in equal-channel angular pressing," Acta Materialia, vol. 46, no. 5, pp. 1589-1599, 1998.

[15] R. Z. Valiev and T. G. Langdon, "Principles of equal-channel angular pressing as a processing tool for grain refinement," Progress in Materials Science, vol. 51, no. 7, pp. 881-981, 2006.

[16] A. T. Abbas, A. E. Ragab, E. A. El-Danaf, and E. A. Al Bahkali, "Effect of equal-channel angular pressing on the surface roughness of commercial purity aluminum during turning operation," Proceedings of the Institution of Mechanical Engineers, Part B: Journal of Engineering Manufacture, 2016.

[17] S. S. Khamis, M. A. Lajis, and R. A. O. Albert, "A sustainable direct recycling of aluminum chip (AA6061) in hot press forging employing response surface methodology," Procedia CIRP, vol. 26, pp. 477-481, 2015.

[18] B. L. Chan and M. A. Lajis, "Recycling of aluminium 6061 ChipThrough cold compression," International Journal of Engineering \& Technology, vol. 15, no. 4, 2015.

[19] J. R. Duflou, A. E. Tekkaya, M. Haase et al., "Environmental assessment of solid state recycling routes for aluminium alloys: can solid state processes significantly reduce the environmental impact of aluminium recycling?" CIRP Annals-Manufacturing Technology, vol. 64, no. 1, pp. 37-40, 2015.

[20] H. Tebassi, M. A. Yallese, R. Khettabi, S. Belhadi, I. Meddour, and F. Girardin, "Multi-objective optimization of surface roughness, cutting forces, productivity and Power consumption when turning of Inconel 718," International Journal of Industrial Engineering Computations, vol. 7, no. 1, pp. 111-134, 2016.

[21] K. Kadirgama, M. M. Noor, N. M. Zuki et al., "Optimization of surface roughness in end milling on mould aluminium alloys (AA6061-T6) using response surface method and radian basis function network," Jourdan Journal of Mechanical and Industrial Engineering, vol. 2, no. 4, pp. 209-213, 2008.

[22] K. Kadirgama, M. M. Noor, M. M. Rahman, M. R. M. Rejab, C. H. C. Haron, and K. A. Abou-El-Hossein, "Surface roughness prediction model of 6061-T6 aluminium alloy machining using statistical method," European Journal of Scientific Research, vol. 25, no. 2, pp. 250-256, 2009.

[23] D. C. Montgomery, Design and Analysis of Experiments, John Wiley \& Sons, New York, NY, USA, 2013.

[24] G. E. P. Box and D. W. Behnken, "Some new three level designs for the study of quantitative variables," Technometrics, vol. 2, no. 4, pp. 455-475, 1960.

[25] M. Haase, N. Ben Khalifa, A. E. Tekkaya, and W. Z. Misiolek, "Improving mechanical properties of chip-based aluminum extrudates by integrated extrusion and equal channel angular pressing (iECAP)," Materials Science and Engineering A, vol. 539, pp. 194-204, 2012.

[26] A. I. Selmy, A. M. El-Gohry, M. I. Abd El Aal, and M. A. Taha, "Characteristics of solid state recycling of aluminum alloy (AA6061) chips by hot extrusion," in Proceedings of the International Conference of Engineering Sciences and Applications, vol. 1, pp. 316-323, Aswan, Egypt, 2016.

[27] A. I. Selmy, M. I. Abd El Aal, A. M. El-Gohry, and M. A. Taha, "Solid-state recycling of aluminum alloy (AA-6061) chips via hot extrusion followed by equal channel angular pressing (ECAP)," The Egyptian International Journal of Engineering Sciences and Technology, vol. 21, pp. 33-42, 2016.

[28] M. Hu, Z. Ji, X. Chen, and Z. Zhang, "Effect of chip size on mechanical property and microstructure of AZ91D magnesium alloy prepared by solid state recycling," Materials Characterization, vol. 59, no. 4, pp. 385-389, 2008. 

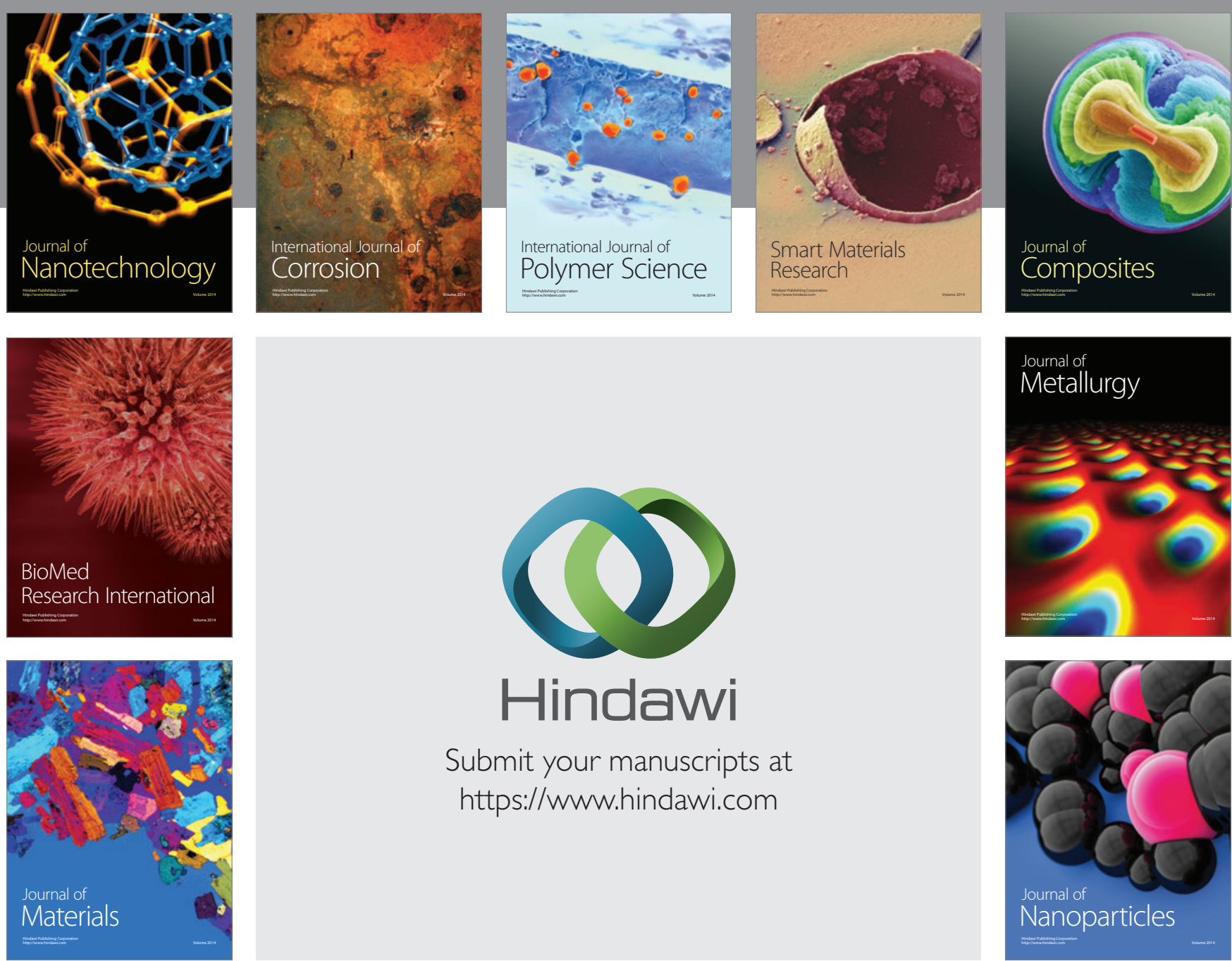

\section{Hindawi}

Submit your manuscripts at

https://www.hindawi.com

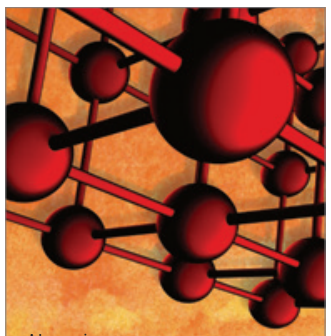

Materials Science and Engineering
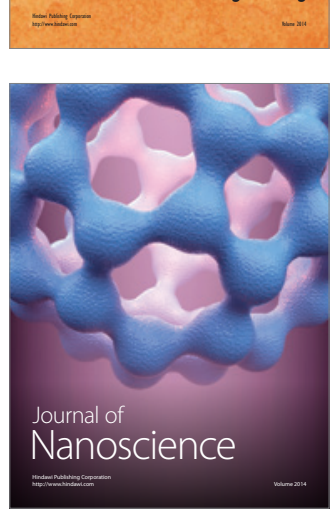
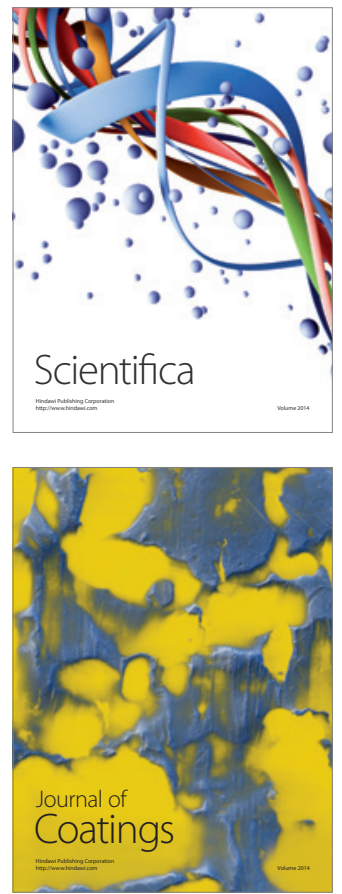
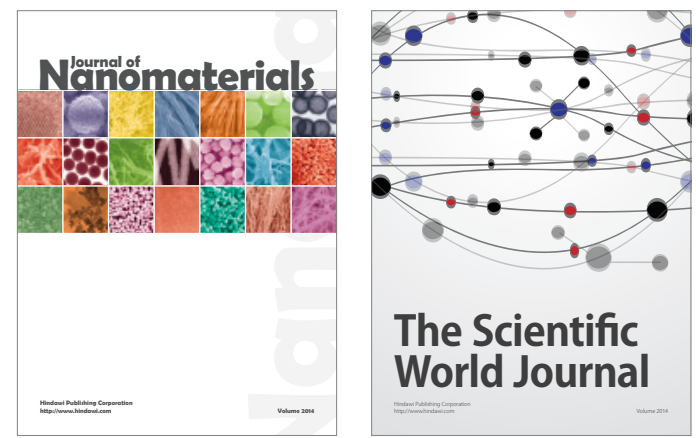

The Scientific World Journal
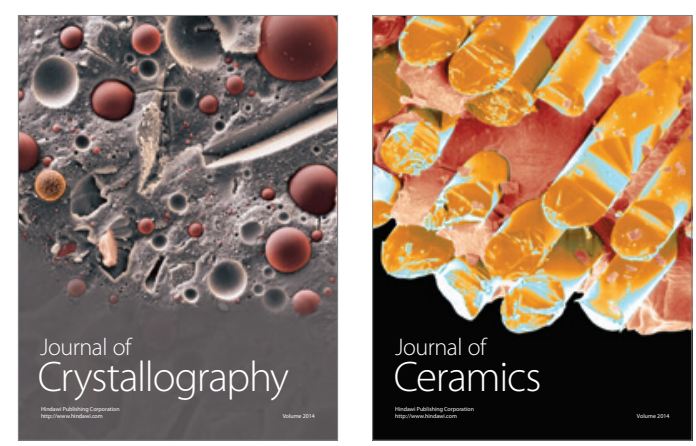
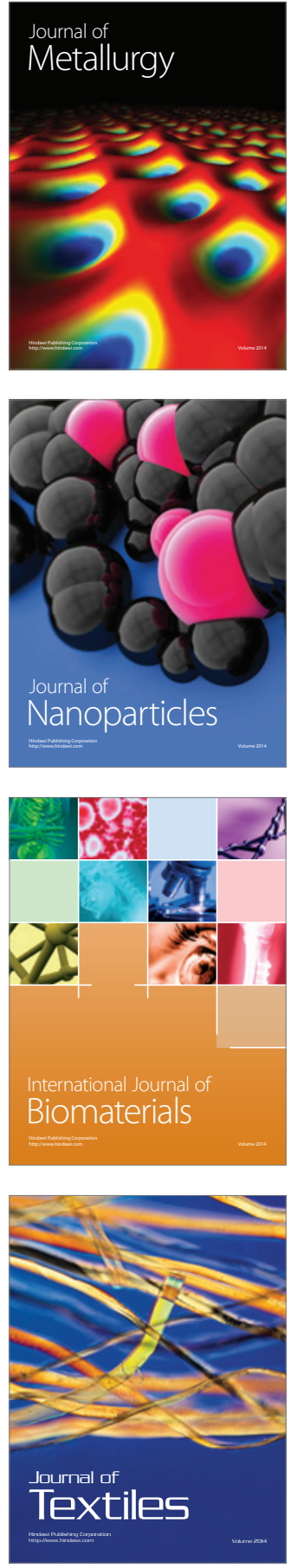